\title{
Sustainable development of organizations in modern conditions
}

\author{
Dina Prostova, Natalya Sosnina*, and Anna Tikhonova \\ Ural State University of Economics, 8 Marta Str., 62, 620144 Ekaterinburg, Russia
}

\begin{abstract}
The article studies with the theoretical issues of sustainable development of organizations in modern conditions. The authors show that through achieving efficiency and effectiveness, an organization can thus ensure its sustainable development, and also provide a model of "4K ensuring the sustainable development of market entities". Logical, expert, and system analysis were used as research methods. The specifics of the problem of determining the factors that affect the ability of economic entities to form a sustainable development strategy in modern conditions determined the structure of the study. The authors analyze various interpretations of the term "sustainability" and present the main factors affecting the development of economic systems in the form of a model of the organization's functioning, taking into account the influence of environmental factors. In conclusion, the article substantiates the following: the presented model proves that to meet the needs of their stakeholders, organizations need to have certain capabilities, the effectiveness of which they can achieve by improving their management system.
\end{abstract}

\section{Introduction}

At the present stage of technological processes implementation in all spheres of economic activity, the issues of intelligence and knowledge intensity are becoming increasingly important for the development of businesses and households, as well as the public sector.

Strengthening competitiveness at the global level, ensuring the effectiveness of the national economy, and striving for sustainable economic development lead to the formation of micro-, meso - and macroeconomic factors that affect both regional development and the development of individual economic entities.

When analyzing the economic literature, one can find different definitions of the market [1], [2], [3], [4]. Each interpretation uses different terminology and dwells upon certain features, but they all define the market as a set of relations in the process of exchanging something.

The entire value chain of various types of economic activity is based on the totality of the activities of individual organizations and/or their structural divisions. If an economic entity does not have the necessary competencies (or they are at a low level of development), it becomes critical for the market or industry. Therefore, the subject urgently

\footnotetext{
*Corresponding author: natalya789@yandex.ru
} 
needs to develop these competencies or acquire them. In this regard, to understand the importance of certain competencies, firms need to distinguish clearly between the categories of "efficiency" and "performance" when analyzing its activities. The term "effectiveness" is the degree of achievement of goals and "efficiency" is the ratio of the achieved (actual outcome) and the cost of it. That is, in essence, "effectiveness" is the measure of the implementation of the strategy, whereas "efficiency" is the assessment of resources usage.

In order to achieve the intended result, any activity of economic entities should be adjusted taking into account the consistency of available resources and the allotted time with the influence of the external environment.

If the specified result is achieved in time, the activity is characterized perfect. When the result is correlated with the resources spent, there is an economic justification for the activity. Public (social) justification implies the ratio of the result and the restrictions that are imposed on the activity by the influence of the external environment. The balance of all the above factors results in the category of "efficiency".

Thus, in order to improve performance, initiation and production should prevail, and in order to increase efficiency, administration and integration should prevail. Therefore, in order to develop sustainably, the firm must strive to ensure that both parameters are met.

According to the authors, the stakeholder approach in the implementation of strategic relations based on trust and long-term mutually beneficial partnership leads to the formation and strengthening of an effective market position of economic subjects in modern conditions.

Through achieving efficiency and effectiveness, the organization can thus ensure its own sustainable development.

The above discussion summarizes the authors' opinion that the key to the success of market subjects in modern conditions is to focus on the stakeholder approach in implementing strategic interactions to create and strengthen long-term relationships based on the principles of mutually beneficial partnership and trust. Through the stakeholder relationship, subjects can ensure their effectiveness and efficiency through the combination of "4C" (Fig. 1).

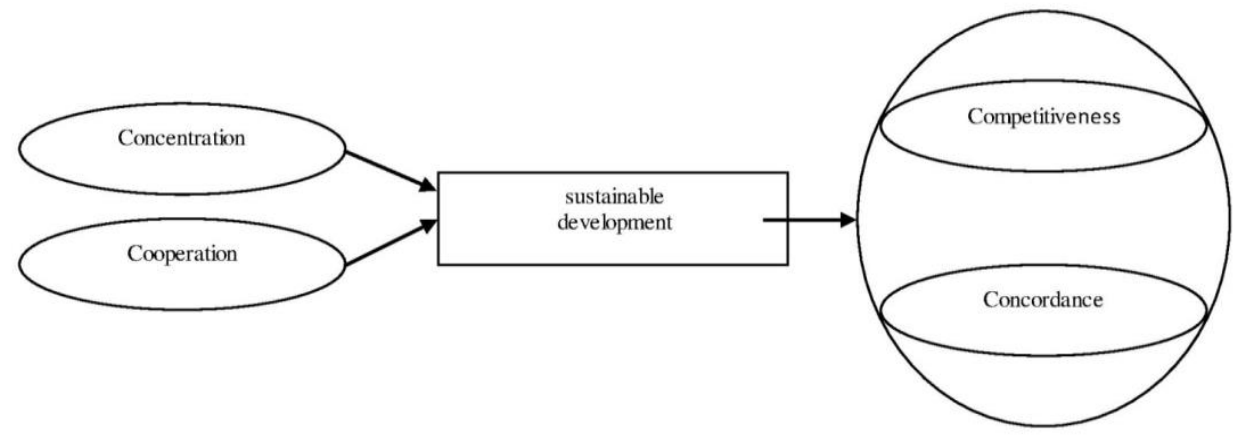

Fig. 1. Concept of economic subjects' sustainable development

At the beginning, the key processes are concentration and cooperation. In the first case, there is the localization of resources in a certain territory, and in the second one there is the involvement of related industries and local institutions and maintaining the competitiveness of their products in the domestic and foreign markets. From these two components, due to the complementarity and specialization of stakeholders, the productivity of economic 
subjects increases, forming their concordo - and competitiveness. Concordance is manifested in the consistency of the goals of stakeholders to ensure their sustainable development [5].

Thus, the ability to ensure long-term effective functioning is a key factor in the development of any economic entity. The amount of positive impact of this resource on the national economy will also depend on how effectively internal management will be used.

According to the authors, in many organizations, the current management decisionmaking mechanisms do not meet the conditions of modern Economics, and, consequently, are not sufficiently effective. This indicates the need to improve such a system-forming element as scientific and methodological tools that form the conditions for effective management within the framework of existing economic laws.

\section{Materials and Methods}

The object of the research is the factors that affect the sustainable development of organizations in modern conditions.

Logical, expert, and system analysis were used as research methods. The specifics of the problem of determining the factors that affect the ability of economic subjects to form a sustainable development strategy in modern conditions determined the structure of the research. The authors analyzed different approaches of sustainability concept in order to form the authors' attitude to the topic under consideration.

The study consisted of the following stages:

- analysis of periodical research on sustainable development issues;

- search for factors affecting sustainable development in modern conditions;

- the development of the authors' vision on the issues under consideration.

\section{Results and Discussion}

According to the authors, the firm's sustainable development management strategy should not be separated from the management system of its activities, since it will lead to conflicts between the goals and objectives of individual structural elements. Disjointed management, therefore, will result in efficiency and effectiveness decrease. Therefore, first of all, any firm must ensure the unity of planning and management systems, correcting them by conducting a comprehensive assessment of performance.

In this regard, the authors analyzed the concept of "development" used in scientific Russian and foreign literature [6], [7], [8]. Basically, there were two main visions of the concept under consideration:

1) Development as an object changing process.

2) Development is an object qualitative change to a higher level.

In the first vision, development can be understood as:

- $\quad$-dynamic changes in the system of a progressive nature [9];

- multidimensional processes that lead to reorientation of the system or its reorganization [10];

- changes in ideal material objects, characterized by directivity and irreversibility [11].

- Unfortunately the system in this case can move not only in evolutionary development, but also may tend to degrade to a lower state.

- The second vision faces the development as the following:

- this is a peculiar kind of change meaning reconstruction in quality that results in a higher stage [12]; 
- $\quad$ increased growth in income, production, and employment indicator [13];

- change in the system potential with the previous resources, taking into account the influence of destabilizing factors (both external and internal) [14];

- processes of progressive purposeful changes in the composition, interactions and position of elements of the production system, in its quality of functioning and level, leading to an increase in its efficiency [15].

Based on the advantages and disadvantages of various approaches identified in the course of the analysis, development in this article will mean the processes of their qualitative progressive changes that increase the abilities and capabilities of objects.

Further, the authors conducted the analysis of the "sustainability" concept. The main approaches to the interpretation of this term are shown in figure 2 (Fig. 2).

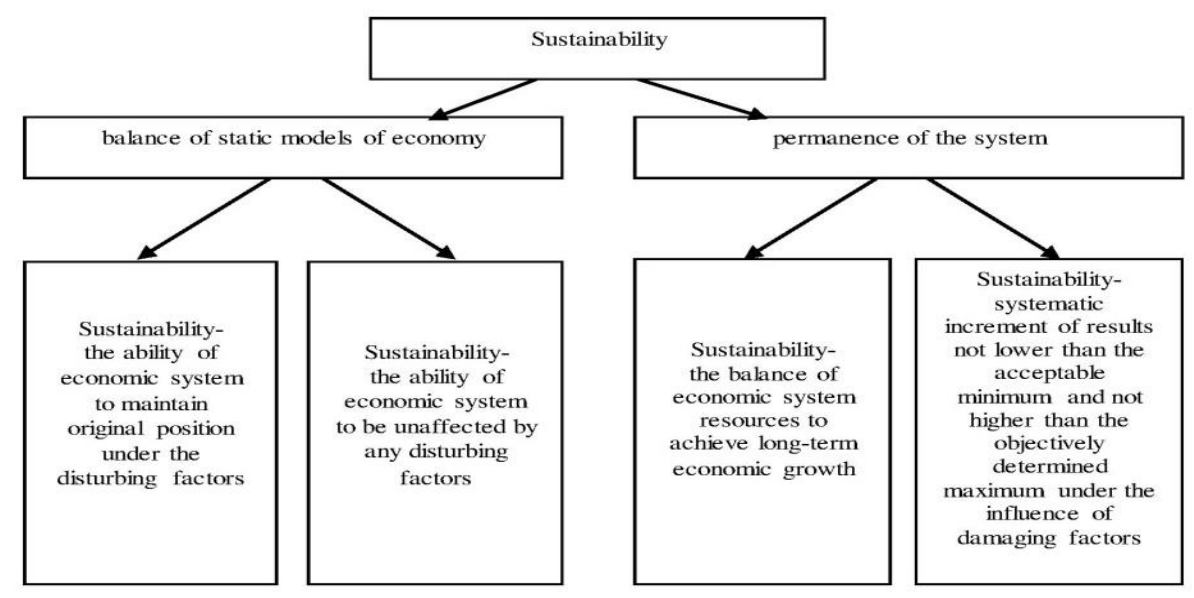

Fig. 2 Sustainability in the interpretation of various studies [16], [17], [18], [19], [20] [21], [22] [23]

According to D. R. Hicks, only strategic economic models that do not coincide with the expectations of other market participants are characterized by stability. And taking expectations into account gives a dynamic character to the model [24]. If the actual results of economic development and individual expectations do not coincide, then "disturbing factors" that cause the system to unbalance are infected. Many Russian researchers agree with it [25], they mean the stability of the quality of a stationary system that is not affected by any factors during operation. It is considered that an emergency situation is impossible in such conditions.

According to other studies, only a system that maintains its state under the pressure of negative influences can be considered stable. A. M. Lyapunov, for example, writes that the system is sustainable if it is able to get closer to the trajectory that it had before the disturbances from the external environment [26]. O.V. Mikhalev defines sustainability as the characteristic of the system connected with its ability to remain stably in the external conditions [27]. E. I. Iglina's understanding is the balance remaining system both in terms of internal and external factors got by ensuring the stability of its individual elements [28].

The third approach is to determine sustainability without reference to its static state. N. A. Kulbaka, for example, writes that sustainability is a state of economic resources characterized by equality and balance, providing in the long term normal conditions for economic growth and stable profitability, taking into account internal and external factors [25]. A. N. Azrilyan understands the resistance as durability, uniformity and resistance to the risk of losses [29].

In V. M. Bautin and A. A. Chernikov' view sustainability happens if production potential is use entirely, so it ensures both profitability and production development, 
material and technical base reconstruction, it guarantees positive social atmosphere in the working place and environmental friendly conditions [30].

Figure 3 presents the sustainability classification based on an analysis of the economic literature (Fig. 3) [31], [32], [33], [34], [35].

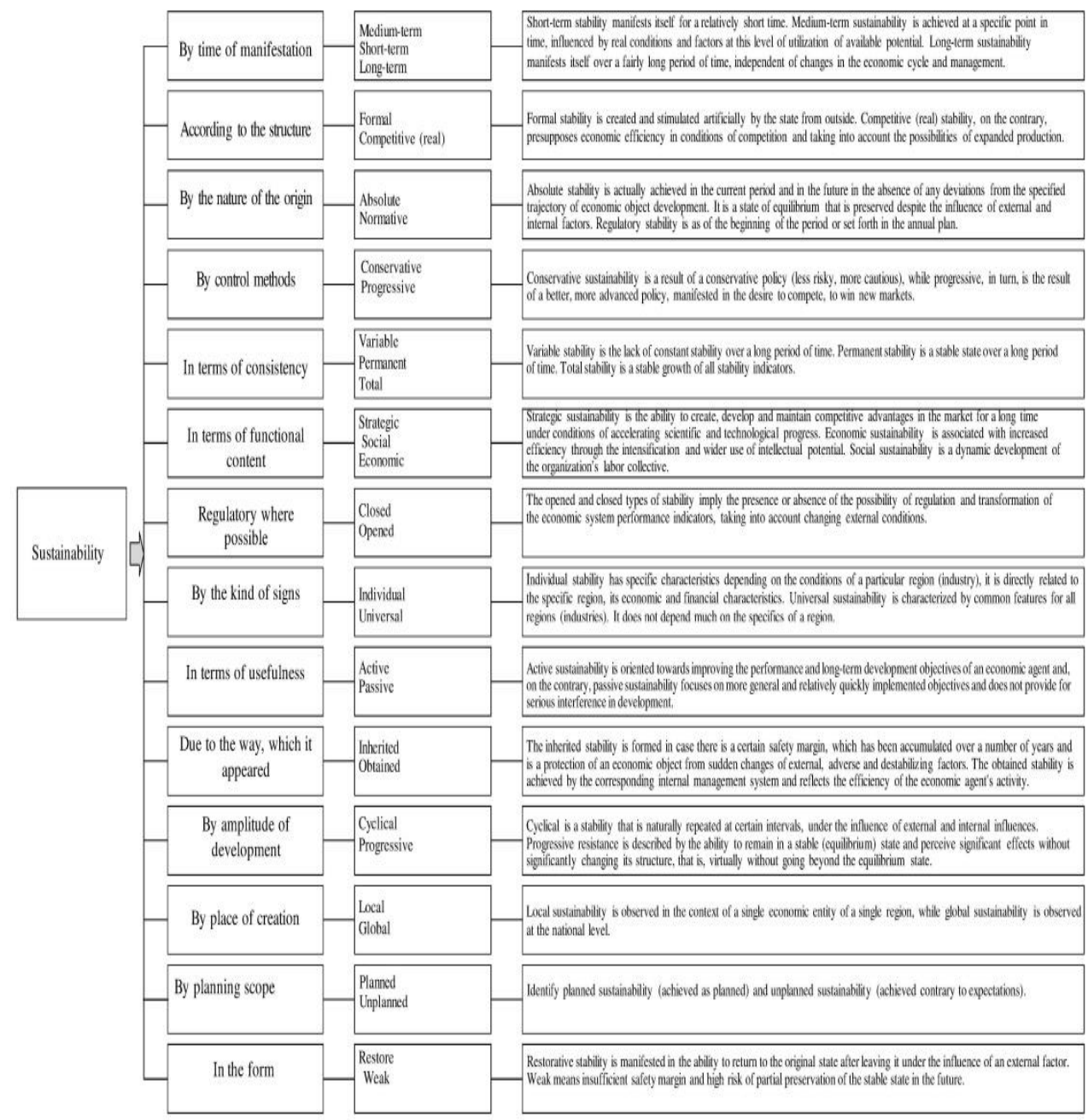

Fig. 3. Sustainability Classification

Thus, by analyzing the different approaches, it is possible to identify the positions that are characteristic of the term "sustainability":

1. balanced system able to function under external violation, resulting in stability, continuity and risk - resistant problems;

2. system able to resist damaging conditions;

3. system able to communicate with its to guarantee long-term growth.

In order to link the terms "sustainability" and "development", a number of studies have been carried out [22], [36], [37], [38], [39], [40], to identify two positions on the relationship between these terms. Representatives of the first position stress the absence of development in terms of conservative conditions and stability. The second position underlines the opportunities for development taking into consideration the concept of the 
both process and qualitative changes stability. This position is studied in this research.

Therefore, the sustainable development of an organization is a process of purposeful formation by the organization of its capabilities into a single system taking into account the variability of environmental requirements.

A factor (lat. factor - making, producing) is the cause, driving force of a process, a phenomenon that determines its nature or individual features [29]. Thus, the sustainable development of an organization is achieved by taking into account and overcoming certain factors that determine the conditions of its operation and its final result.

Figure 4 shows the main factors affecting the development of economic systems (Fig.4)[41], [42], [43], [44], [45].

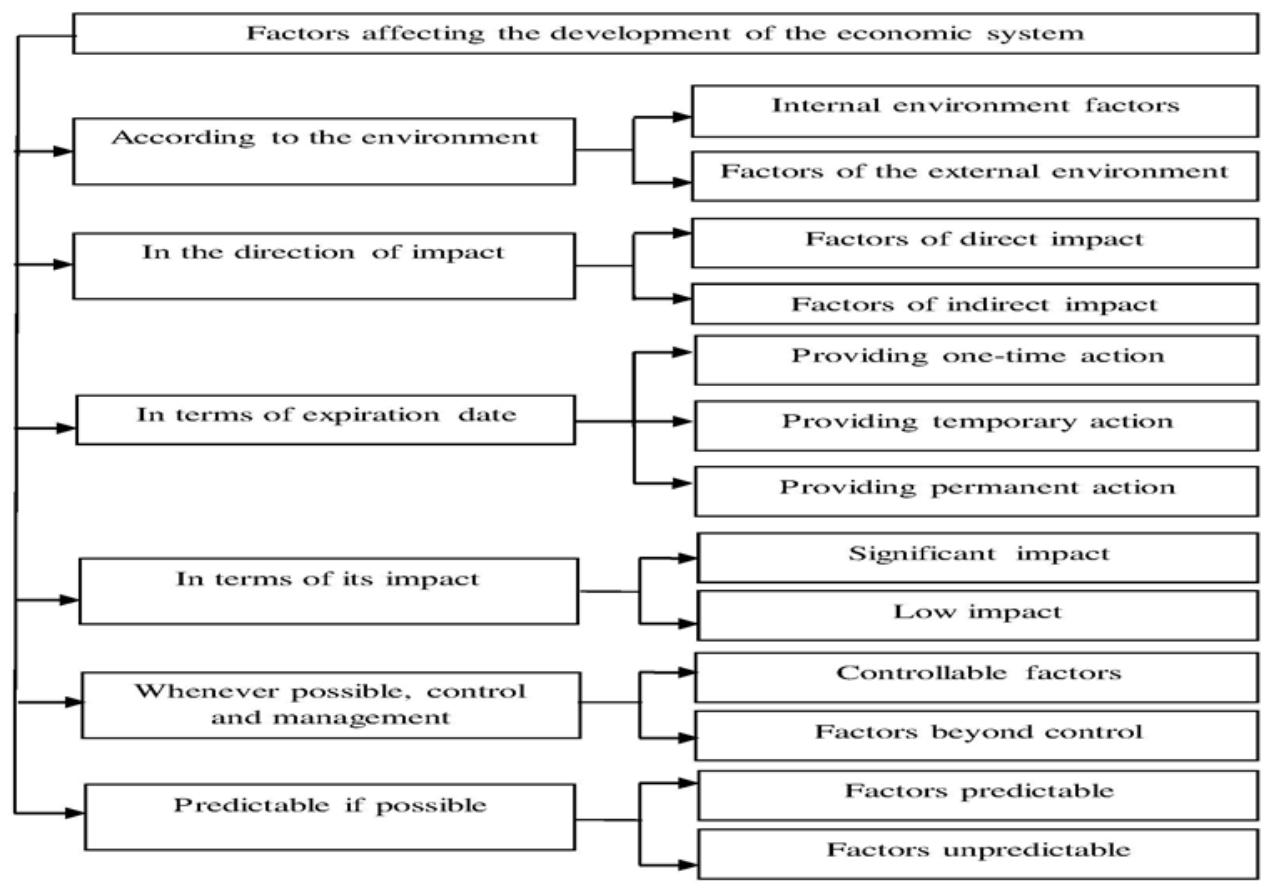

Fig. 4. Factors affecting the development of the economic system

According to the stakeholders' theory and strategic management framework, the above classifications allow us to identify the following areas of relationships between economic entities that can affect their sustainable development:

1. Relationship with consumers

2. Relationship with suppliers

3. Technological links

4. Interaction of divisions within the subject.

It should be noted that any economic entity should be considered together with its internal environment. By internal environment we mean material and non-material resources, staff and the system of management. Internal communications, which contribute to the creation of the environment necessary for success by increasing management efficiency should be definitely stressed.

Due to the fact that any organization is an open system with a complex hierarchy closely interacting with the external environment, the generalized model of its functioning will be a model built on the system principle (Fig. 5). 


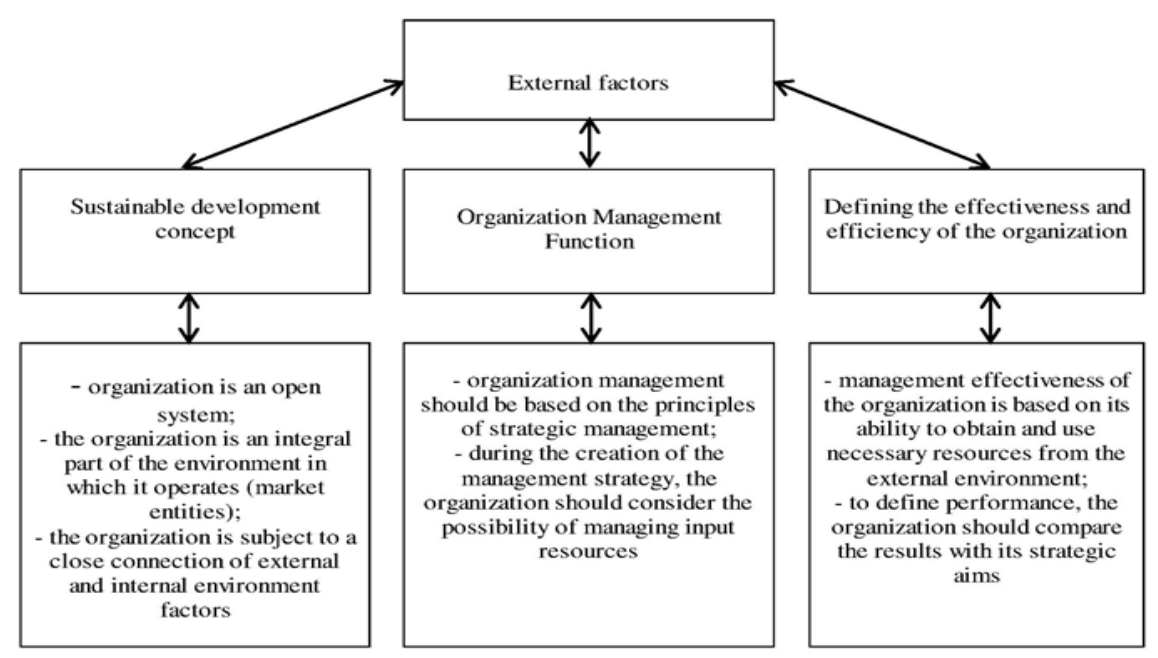

Fig. 5. Functioning model of the organization based on the impact of environmental factors

\section{Conclusion}

The model proposed by the authors makes it possible to form and improve the sustainable development strategy of the firm through:

1. Highlight key opportunities for the firm in the conditions dictated by the market for its operation;

2. Identify the trends of development taking into account the dynamics of external environment factors affecting the functioning of the company;

3. Creation of the most significant key indicators accurately and objectively characterizing the current state of the competitive and correspondent capacity of the firm, as well as the prospects and problems of their development;

4. Defining a list of parameters capable of changing the chord capacity, thus increasing its stability;

5. Development and implementation of alternative options for adaptation of the company to the dynamics of the external environment;

6. Taking measures to find and solve the problems of company's sustainable development through integration processes with stakeholders.

Thus, considering the principles of corporate capacity in their strategy, economic entities get an opportunity to form an effective base of strategies for implementation of common goals and objectives and satisfaction of stakeholders' interests, which will lead to sustainable development of both the entity and the national economy in the long term.

\section{References}

1. A. Sullivan, Steven M. Sheffrin, Economics: Principle in Action. Upp. S.R., (2003).

2. K.R. McConnell, Economics: Principles, Problems and Policy, (2007)

3. W. Petty, A. Smith, D. Ricardo, Anthology of Economic Classics, (1993)

4. F. Kotler, Fundamentals of Marketing, (2016)

5. A.D. Tikhonova, AG Mokronosov, Kr. ek., 12 (2018) 
6. N. T. Agafonova, P. A. Islyaev, Ek. Prev Env. Wed, 1-2 (1995)

7. O.V. Aleshkina, Izv. Grew up. state ped. un-ta., 24 (2008)

8. Yu. S. Alferov, Ped., 7

9. E.N Kucherova, West. OSU, 6 (2009)

10. S.A Dyatlov, Investment concept of development of Russia (1997)

11. A.V. Korotaev, AS Malkov, East. and modern, 1 (2007)

12. B. A. Raizberg, L. Sh. Lozovsky, E.B. Starodubtseva, Modern Economic Dictionary (2006)

13. M.P. Todaro, Economic development, (1997)

14. D.A. Gainanov, Vopr. management West. BIST, 2 (2) (2009)

15. V.P. Chetvertakova, I.M. Chetvertakov, Economic growth and development, http: //institution.tsom/

16. N.R. Kelchevskaya, Assessment of the economic sustainability of a state university, Un. ex. 4 (23) (2002)

17. N.S. Kolotova, Stability of the development of transitive economics: diss. Ph.D. Chel, (2005)

18. E.V. Makarova, Stability of the economic system in the context of globalization of the world economy: dis. c. e. n. East-Sib. state technol. un-t. St. -Ude, (2006)

19. G.A. Krayukhina Methods for assessing the sustainability and development of an industrial enterprise and ways out of a crisis situation (2010)

20. Yu. V. Sirotova, Sustainability of enterprise development in a transitional economy: dis. Ph.D, (2009)

21. A. G. Granberg, V. I. Danilova-Danil'yan, M. M. Tsikanova, E. S. Shopkhoeva, Economics, Strategy and problems of sustainable development of Russia in the XXI century (2002)

22. A. D. Ursul, Bulletin of the Russian Academy of Sciences. Use and oh. nat. res. in Ross., 1 (2005)

23. V. K. Chertykovtsev and A. N. Bogusonov, The weight. Sar. s. e. un. (2006)

24. J. Hicks, A Contribution to the Theory of the Trade Tsitsle,(1950)

25. V. V. Kul'baka, D. A. Kononov, I. V. Chernov, P. E. Roshchin, O. A. Shuligina, Scenario Study of Complex Systems: Analysis of UBS Group Control Methods, 30.1, 154 (2010)

26. A. M. Lyapunov, General problem of the stability of motion, (1950)

27. O.V. Mikhalev, Economic sustainability of economic systems: methodology and practice of scientific research and applied analysis, (2010)

28. E.I. Iglina, Mun. ow., 4 (2003)

29. A. N. Azriliyana, Big Economic Dictionary. Moscow, 7 (2007).

30. VM Bautin, AA Chernikova, Economic sustainability and profitability of dairy enterprises (2002)

31. I. Sergeev, T. Ponomarenko, Man. th. and st. for rur. beads. and infr. Virgins, 2 (2011)

32. V. A. Vasilenko, Creative management of the development of social and economic systems (2010)

33. S. M. Anpilov, Ek. and exercise, 5 (90) (2012)

34. O. V. Zetkina, M. Aud UNITI, 134 (2003) 
35. R.A. Eremeychuk, Ek. Rozv, 2 (22) (2002)

36. T. A. Akimova, Yu. N. Moseikin, Economics of sustainable development, (2009)

37. D. A. Gaynanov, Vopr. ex. West. BIST, 2(2) (2009)

38. E. Kartaeva, N. Rodina, O. Yakovlev, Mun., 4 (2003)

39. T. I. Kostina, N. M. Mamedov, M. A. Kuvshinov, Mol. uch., 7(1) (2011).

40. GA Ugolnitskiy, Hierarchical Management of Sustainable Learning, (2010)

41. N. Govarova, Pr. theor. and so on. Heb. ek. g., 4 (2006)

42. S. V. Golubev, University as a socially responsible partner of the territory (based on the materials of the project "University and Community") (2011)

43. S.I .Plaksiya, Experience in building a university strategy. Retz. on the book. Higher education: desired and real (2008)

44. S. K. Piliev, E. P. Tszkhorvedov, Opportunities for sustainable development, (2001)

45. O.B. Veretennikova, N.V. Drantusova, A.K. Klyuev and others, ed. E. A. Knyazeva, A. K. Klyueva, Development of the strategy of an educational institution: method, (2007) 